\title{
Adolescents with Internet Gaming Disorder are more likely to have Lower Score of Cognitive Function: A Cross-sectional Study among Junior High School Students in Yogyakarta, Indonesia
}

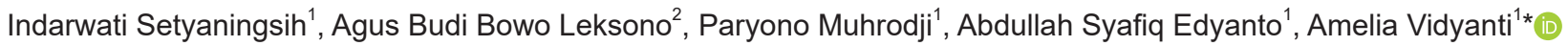 \\ ${ }^{1}$ Department of Neurology, Faculty of Medicine, Public Health and Nursing, Universitas Gadjah Mada, Yogyakarta, Indonesia; \\ ${ }^{2}$ Department of Neurology, Hermina Hospital Mekarsari, Bogor, West Java, Indonesia
}

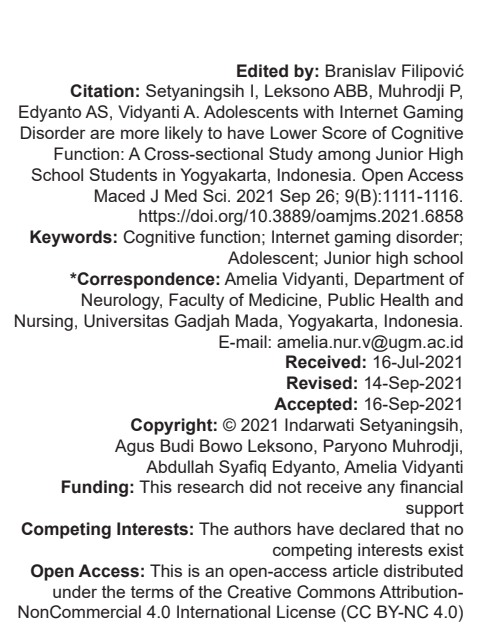

\section{Introduction}

Internet gaming disorder (IGD) is characterized by the individual's failure to control the use of the internet/video games. IGD can result in life distress and dysfunctions affecting academic performance, social interaction, occupational interest, and behavioral problems [1]. DSM-V had listed several proposed criteria for IGD, requiring at least five of the following criteria for a 12-month period: (1) Preoccupation with Internet games; (2) withdrawal symptoms when internet gaming is removed; (3) need to spend more time playing online games; (4) unable to control Internet gaming; (5) lack of desire in previous hobbies and entertainment; (6) continued excessive use of Internet games despite knowledge of psychosocial problems; (7) deception of family members, therapists, or others over the quantity of time spent on the internet gaming; (8) playing internet games to escape or ease a negative mood; and (9) lost of significant relationship, job, or educational/career opportunities [2]. The pathological use of the internet is manifested by the excessive or uncontrollable desire and habit of internet use that leads to impairment and distress [3].

The prevalence of IGD can rapidly increase as the technology advances, notably due to the ease of internet access and the expansion of internet coverage [4]. Based on the previous studies, the prevalence of IGD in the Netherlands ranged from $3.8 \%$ to $5.4 \%$ [5], Slovenia $2.5 \%$ [6], South Korea 5.9\% [7], and Germany 5.7\% [8]. The prevalence of IGD globally varies according to the age group [9], from $0.7 \%$ to $15.6 \%$ among adults [10] and $0.6-19.9 \%$ among adolescents [11].

In Indonesia, the prevalence of IGD among adolescents was quite high, reaching $10.15 \%$ [12]. This may be related to increased internet usage in Indonesia from $0.9 \%$ in 2000 to $17.1 \%$ in 2014 . A prior study showed that approximately $80 \%$ of adolescents (comprised of junior and senior high school students) in Indonesia use the internet on a daily basis [13]. 
Adolescents are the most vulnerable age group for internet addiction and gaming disorders, as they can develop more serious complications than the other age groups. Adolescents may be trapped in the cyber world, suffer psychological panic, and eventually destroy their personal and social networks [14]. Moreover, they may be more engaged with - and willing to learn about - new technology solutions and platforms. This activity may result in aggressive and excessive behaviors [15].

Furthermore, individuals with IGD have been associated with several problems such as cognitive dysfunction, increased stress or anxiety, and reduces academic achievements leading to decreased job performance and poor quality of life [16], [17]. A systematic review of evidence published in Chinese reported that urban adolescents were 2 times more likely to develop IGD and other various problems than rural adolescents [18]. These may be due to larger communities in urban areas could lead to a weaker social cohesion, individualism, and a diminished sense of kinship than in rural areas [19], [20].

Although several studies in Indonesia have already revealed the prevalence, characteristics, and impacts of IGD [9], [12], [21], none of these studies focused on the relationship between IGD and cognitive function among adolescents, particularly in urban area. A recent study conducted among young adults in Korea showed that individuals with IGD had lower verbal comprehension, processing speed, and working memory compared with non-gamers [22]. The previous study also demonstrated that younger individuals with IGD demonstrated impaired response inhibition, higher degrees of impulsiveness and anger/aggression, and poor quality of life [16]. By knowing these evidences, a study focusing on the association of IGD with cognitive performance among adolescents in Indonesia is beneficial. The present study aimed to investigate the association between IGD and cognitive function among junior high school-students in Indonesia. The findings of this study could provide additional evidence supporting the link between cognitive function and IGD among adolescents, particularly in Indonesia.

\section{Methods}

\section{Study design and participants}

This was a cross-sectional study. A cluster random sampling method was conducted to recruit participants from October 2018 to May 2019 in two randomly selected junior high schools in Yogyakarta, Indonesia. The sample size was determined by the standard deviation from prior study with the $\alpha$ of $5 \%$ and $\beta$ of $20 \%$. The minimum sample size for each group was 37 participants. Therefore, 74 participants were at least needed for the present study [23].

The inclusion criteria were:(1) Junior high school students with maximum age of 15 years and (2) had IGD or non-IGD based on the Game Addiction ScaleIndonesian version (GAS-7 Ina) [24]. The exclusion criteria were: (1) Presence of pain, (2) history of intracranial infection, head trauma, and cerebral palsy, and (3) history of psychiatric disorders and substance abuse. In total, we were able to recruit 142 participants consisted of 71 students with IGD and 71 with non-IGD.

\section{Measurements}

The study was conducted in two steps. At the first step, IGD and non-IGD participants were determined based on the GAS-7 Ina. GAS-7 Ina is a questionnaire to measure online game addiction developed for Indonesian children and adolescents. GAS-7 Ina has good validity and reliability, with sensitivity of 0.792 and specificity of 0.792 for boys, and sensitivity of 0.787 and specificity of 0.75 for girls, and Cronbach's alpha value of 0.770 [24]. It consists of seven questions covering several aspects: Salience, tolerance, mood modification, withdrawal, relapse, conflict, and problems. Each question was measured on a 5-point Likert scale. Mid-point was used as a cutoff point. Subject with score $\geq 4$ was considered as IGD and those with score $<4$ as non-IGD [25].

At the second step, participants' cognitive function was assessed with Modified Mini Mental State Examination for Children-Indonesian version (MMMSEC-Ina) questionnaire. The MMMSECIna assessed various cognitive domains with the maximum score of 37 , of which 12 for orientation, three for registration, seven for calculation/attention, three for recall, and 12 for language. The MMMSECIna has $83 \%$ sensitivity, $85 \%$ specificity, $94 \%$ positive predictive value, $65 \%$ negative predictive value, and $83 \%$ accuracy [26]. The cutoff score for cognitive impairment in age group of $>13$ years old was 32 [27].

We collected demographic characteristics including age, sex, and body mass index (BMI). The participant's BMI was measured by the formula: The participant's body weight (in kilograms) divided by the square of their height (in meter squares). BMI was classified in this study according to the WHO guidelines for the Asian population: Those with a BMI of $<18.5 \mathrm{~kg} / \mathrm{m}^{2}$ were considered underweight, those with a BMI of $18.5-22.9 \mathrm{~kg} / \mathrm{m}^{2}$ were considered normal, those with a BMI of $23-27.4 \mathrm{~kg} / \mathrm{m}^{2}$ were considered overweight, and those with a BMI of more than $27.5 \mathrm{~kg} / \mathrm{m}^{2}$ were considered obese [28].

In addition, we also obtained information related to internet games, including gaming duration, gadgets type, and game genre. The previous study mentioned that the mean time spent for addicted 
gamers was $3.4 \mathrm{~h} /$ day [29]. Therefore, in the present study, we classified daily gaming length into two categories: $3 \mathrm{~h} /$ day and $>3 \mathrm{~h} /$ day. We further classified the gadgets type into smartphone users, personal computer/Console users, and both, as these were the most frequently used gaming devices in Indonesia [9]. To measure the gaming variety, we categorized gaming genre into Multiplayer Online Battle Arena (MOBA), Massive Multiplayer Online Role-Playing Game (MMORPG), Massive Multiplayer Online First-Person Shooter/Third-Person Shooter (MMOFPS/TPS), and other based on a prior study which listed the most popular video game genres among adolescents [30].

\section{Statistical analysis}

Descriptive analysis was performed to identify the differences between IGD and non-IGD based on the baseline characteristics. Unpaired t-test was performed to determine the statistical differences of each domain of cognitive function between IGD and non-IGD. The crude odds ratios (OR) of confounding variables associated with cognitive dysfunction were measured using bivariate analysis. Multiple linear regression analysis was performed to measure the contribution of IGD and its associated factors with cognitive function score after controlling covariates. All statistical analyses were conducted using IBM SPSS Statistics version 26 ((IBM Co. Ltd, NY, USA), with $p<0.05$ considered as statistically significant.

\section{Ethical consideration}

Ethical approval for this study was obtained from the Medical and Health Research Ethics Committee, Faculty of Medicine, Public Health and Nursing, Universitas Gadjah Mada, Yogyakarta, Indonesia with the approval number: KE/FK/1381/EC. Study subjects and their parents were given explanation related to the objective, procedure, benefits, and risks of the study. The subjects and their parents who agreed to participate in the study then were required to sign an informed consent.

\section{Results}

We recruited 142 participants, consisting of 71 students with IGD and 71 with non-IGD. The mean age for both groups was 14 years old. Baseline characteristics were homogenous, except the gadget type (Table 1).

The total score of cognitive function measured by MMMSEC-Ina showed significant difference between IGD and non-IGD group ( $p=0.003$ ) (Table 2). Analysis was further carried out for every cognitive domain in MMMSEC-Ina. The mean scores for attention, recall, and language domains were significantly lower in the
Table 1: Baseline characteristics of subjects

\begin{tabular}{|c|c|c|c|c|c|}
\hline \multirow[t]{2}{*}{ Characteristics } & \multicolumn{2}{|c|}{ IGD } & \multicolumn{2}{|c|}{ Non-IGD } & \multirow[t]{2}{*}{$\mathrm{p}$} \\
\hline & $\mathrm{n}$ & $\%$ & $\mathrm{n}$ & $\%$ & \\
\hline Age & \multicolumn{2}{|c|}{$14(12-16)$} & \multicolumn{2}{|c|}{$14(13-15)$} & 0.870 \\
\hline \multicolumn{6}{|l|}{ Sex } \\
\hline Male & 30 & 42.3 & 32 & 45.1 & \multirow[t]{2}{*}{0.735} \\
\hline Female & 41 & 57.7 & 39 & 54.9 & \\
\hline \multicolumn{6}{|l|}{ BMI category } \\
\hline Underweight & 26 & 36.6 & 18 & 25.4 & \multirow[t]{4}{*}{0.180} \\
\hline Normal & 36 & 50.7 & 36 & 50.7 & \\
\hline Overweight & 9 & 12.7 & 15 & 21.1 & \\
\hline Obese & 0 & 0.0 & 2 & 2.8 & \\
\hline \multicolumn{6}{|l|}{ Gaming duration } \\
\hline$>3$ h/day & 41 & 57.7 & 35 & 49.3 & \multirow[t]{2}{*}{0.313} \\
\hline$<3 \mathrm{~h} /$ day & 30 & 42.3 & 36 & 50.7 & \\
\hline \multicolumn{6}{|l|}{ Gadget type } \\
\hline Smartphone & 30 & 42.3 & 42 & 59.2 & \multirow[t]{3}{*}{$0.014^{*}$} \\
\hline PC & 17 & 23.9 & 5 & 7.0 & \\
\hline Both & 24 & 33.8 & 24 & 33.8 & \\
\hline \multicolumn{6}{|l|}{ Game genre } \\
\hline MOBA & 10 & 14.1 & 9 & 12.7 & \multirow[t]{5}{*}{0.166} \\
\hline MMORPG & 28 & 39.4 & 20 & 28.2 & \\
\hline MMOFPS/ & 15 & 21.1 & 27 & 38.0 & \\
\hline TPS & & & & & \\
\hline Others & 18 & 25.4 & 15 & 21.1 & \\
\hline
\end{tabular}

IGD group compared to the counterparts ( $p=0.000$, $p=0.000$, and $p=0.003$, respectively). No statistical difference was found in registration and calculation domain (Table 2).

Table 2: The score of cognitive domain for IGD and non-IGD group

\begin{tabular}{|c|c|c|c|}
\hline \multirow[t]{2}{*}{ Cognitive domain } & IGD & Non-IGD & \multirow[t]{2}{*}{$\mathrm{p}$} \\
\hline & Mean (SD) & Mean (SD) & \\
\hline Attention & $10.24(1.20)$ & $11.45(0.81)$ & $0.000^{*}$ \\
\hline Registration & $3.00(0.00)$ & $3.00(0.00)$ & - \\
\hline Calculation & $4.75(2.35)$ & $4.24(2.52)$ & 0.217 \\
\hline Recall & $2.10(0.99)$ & $2.76(0.52)$ & $0.000^{*}$ \\
\hline Language & $11.51(0.83)$ & $11.85(0.36)$ & $0.002^{\star}$ \\
\hline The total score of cognitive function & $31.59(3.70)$ & $33.30(2.92)$ & $0.003^{*}$ \\
\hline
\end{tabular}

Bivariate analysis of cognitive dysfunction and the confounding variables showed no differences between both groups in relation with sex, BMI, gaming duration, gadget type, and game genre (Table 3).

Table 3: Bivariate analysis of cognitive dysfunction and the confounding variables

\begin{tabular}{|c|c|c|c|c|}
\hline \multirow[t]{2}{*}{ Variables } & \multicolumn{2}{|c|}{$\begin{array}{l}\text { Cognitive } \\
\text { dysfunction (MMMSEC }<32 \text { ) }\end{array}$} & \multirow[t]{2}{*}{ OR $(95 \% \mathrm{Cl})$} & \multirow[t]{2}{*}{$\mathrm{p}$} \\
\hline & Yes & No & & \\
\hline \multicolumn{5}{|l|}{ Sex } \\
\hline Male & 24 & 38 & Ref & \multirow[t]{2}{*}{0.996} \\
\hline Female & 31 & 49 & $1.00(0.51-1.98)$ & \\
\hline \multicolumn{5}{|l|}{ BMI category } \\
\hline Underweight & 17 & 27 & $1.11(0.51-2.42$ & \multirow[t]{4}{*}{0.431} \\
\hline Normal & 26 & 46 & Ref & \\
\hline Overweight & 12 & 12 & $1.77(0.70-4.50)$ & \\
\hline Obese & 0 & 2 & - & \\
\hline \multicolumn{5}{|l|}{ Gaming duration } \\
\hline$<3$ h/day & 22 & 44 & Ref & \multirow[t]{2}{*}{0.232} \\
\hline$>3$ h/day & 33 & 43 & $1.54(0.78-3.04)$ & \\
\hline \multicolumn{5}{|l|}{ Gadget type } \\
\hline Smartphone & 27 & 45 & Ref & \multirow[t]{3}{*}{0.949} \\
\hline Computer & 9 & 13 & $1.11(0.57-2.18)$ & \\
\hline Both & 19 & 29 & $1.09(0.52-2.31)$ & \\
\hline \multicolumn{5}{|l|}{ Game genre } \\
\hline MOBA & 9 & 10 & Ref & \multirow[t]{4}{*}{0.100} \\
\hline MMORPG & 23 & 25 & $1.02(0.35-2.96)$ & \\
\hline MMOFPS/TPS & 10 & 32 & $0.35(0.11-1.09)$ & \\
\hline Others & 13 & 20 & $0.72(0.23-2.26)$ & \\
\hline
\end{tabular}

Multivariate analysis with linear regression demonstrated that IGD and playing MMOFPS/TPS significantly affected the cognitive function score (Table 4). The model showed that individuals with IGD 
were more likely to have a lower cognitive function score by 1.40 points compared with their counterparts. On the other hand, individuals playing MMOFPS/TPS were more likely to have a higher cognitive score by 1.40 points than individuals who liked playing other game genre. However, the association between playing MMOFPS/TPS and cognitive function was insufficient to delineate the positive effect due to the confidence interval for this variable passed 1 (Table 4).

Table 4: Multivariate analysis of the variables that affect cognitive function score

\begin{tabular}{lllll}
\hline Variables & $\mathrm{B}$ & $95 \% \mathrm{Cl}$ & $\mathrm{p}$ & Adjusted $\mathrm{R}^{2}$ \\
\hline (Constant) & 33.17 & $32.13-34.21$ & 0.00 & 0.09 \\
IGD & -1.40 & $-2.51--0.29$ & $0.01^{*}$ & \\
Gaming duration & -0.83 & $-1.92-0.27$ & 0.14 & \\
MMOFPS/TPS & 1.40 & $0.19-2.6$ & 0.02 & \\
\hline${ }^{*} \mathrm{p}<0.05$. IGD: Internet gaming disorder, MMOFPS/TPS: Massive multiplayer online first-person shooter/
\end{tabular}

third-person shooter $B$ : Coefficient of Regression. R2: Coefficient of determination.

\section{Discussion}

The present study demonstrated that adolescents with IGD had lower score of cognitive function, particularly in the domains of attention, recall memory, and language. To the best of our knowledge, this is the first study in Indonesia which showed that IGD were more likely associated with a lower score of cognitive function among adolescents.

The present study corroborates previous studies which found that people with IGD had lower intelligence quotient (IQ) and the stop signal test (SSQ) score [16], lower verbal comprehension, processing speed, and working memory [22], as well as had deficit in executive function [31]. Another study also demonstrated the negative effect of internet addiction which caused deficits in working memory, executive dysfunction, and impulsivity [32].

Executive functions are the most affected domain in IGD because evidence from brain imaging studies showed reduction of gray-matter density in regions involved with higher cognitive (executive functions), attention, and motor control [33], as well as decreased cortical thickness in regions associated with decision making, reward/loss processing, and cognitive control (right middle temporal gyrus, precentral gyrus, cuneus, inferior parietal lobe, and orbitofrontal cortex) [34]. Nevertheless, the present study could not investigate the impact of IGD on executive functions due to different methodology. We used MMMSEC to detect any cognitive impairment. MMMSEC was derived from Mini-Mental State Examinations (MMSE), screening tools of higher mental function in adults, which had been modified for use in pediatric setting [35]. MMSE is insensitive to detect impairments in executive functioning and visual construction [36], [37], [38]. Therefore, executive dysfunction may be undetected using MMMSEC.
This study also found that recall memory and language domains were affected in IGD. Correspond to the present study, a prior study conducted in children aged 9-13 years with gaming addiction demonstrated a correlation between gaming addiction with worse episodic memory, basic reading skills, written expression skills, and attention [39]. In addition, adolescents with internet addiction showed the lower verbal comprehension compared with the non-addicted group [40]. The mechanisms underlying these findings may be explained by brain imaging study. The brainMRI studies of IGD patient's revealed reduction of white matter volume and disruption of the functional connectivity in regions associated with learning and memory [33], [41]. Furthermore, higher usage of screen-based media was associated with decreased microstructural integrity of white-matter tracts, which could contribute to language deficits, according to another study [42].

Individuals with IGD were associated with longer time of gaming duration [9], [43], [44]. In the present study, we found no association between gaming duration and cognitive function. Contradictory to our findings, prior study found that the cumulative internet gaming duration was negatively correlated with gray-matter volume of the left ventrolateral prefrontal cortex in IGD subjects [45], indicated that longer time of gaming duration may contribute to executive dysfunction. Further study is needed to delineate the association.

In our study, the association between playing MMOFPS/TPS and cognitive function was insufficient to conclude that playing MMOFPS/TPS had protective effect for cognition. On the other hand, prior study reported that MMFPS player showed better working memory and attention [46]. Nevertheless, this improvement in cognitive function cannot be generalized into enhancement in general cognitive abilities. This finding warrants further investigation.

The present study contributes to providing further evidence for a negative association between IGD and cognitive function in adolescents. This finding could help to advance future research and be useful in clinical practice, particularly in the field of child and adolescent psychiatry. Public health measures should target adolescents with high-internet usage to prevent the negative effect of IGD. Nonetheless, this study had several limitations. First, it only recruited participants from one specific region in Yogyakarta and had a small sample size due to limited funding. Therefore, the findings in the present study need careful interpretation on generalization. Second, the gaming duration was only measured for how many hours per day, not included how many days in a week or a longer duration. The longer duration of gaming exposure would provide more distinct effect for cognitive function. Third, we did not compare the study population between urban and rural. The different culture of population may give 
different findings. Finally, we only used cross-sectional data which could not provide a causal relationship between IGD and cognitive function. Further longitudinal cohort study is needed, particularly in urban and rural population, to delineate the impact of IGD on cognitive performance among adolescence.

\section{Conclusions}

IGD was negatively associated with cognitive function. Junior high school students with IGD in Indonesia had lower score of cognitive function compared with students without IGD, particularly in the domains of attention, recall memory, and language. Clinicians, teachers, and parents should be more aware of the detrimental effect of IGD. Further study with larger sample size, diverse subjects, and wider age range is still needed.

\section{References}

1. Petry NM, Rehbein F, Gentile DA, Lemmens JS, Rumpf HJ, Mößle T, et al. An international consensus for assessing internet gaming disorder using the new DSM-5 approach. Addiction. 2014;109(9):1399-406. https://doi.org/10.1111/add.12457 PMid:24456155

2. American Psychiatric Association. Diagnostic and Statistical Manual of Mental Disorders (DSM-5®). United States: American Psychiatric Association; 2013. https://doi.org/10.1007/ springerreference_179660

3. Shaw M, Black DW. Internet addiction: Definition, assessment, epidemiology and clinical management. CNS Drugs. 2008;22(5):353-65

PMid:18399706

4. Naskar S, Victor R, Nath K, Sengupta C. "One level more:" A narrative review on internet gaming disorder. Ind Psychiatry J. 2016;25(2):145. https://doi.org/10.4103/ipj.ipj_67_16 PMid:28659692

5. Lemmens JS, Valkenburg PM, Gentile DA. The Internet gaming disorder scale. Psychol Assess. 2015;27(2):567. https://doi. org/10.1037/pas0000062

PMid:25558970

6. Pontes HM, Macur M, Griffiths MD. Internet gaming disorder among Slovenian primary schoolchildren: Findings from a nationally representative sample of adolescents. J Behav Addict. 2016;5(2):304-10. https://doi.org/10.1556/2006.5.2016.042 PMid:27363464

7. $\mathrm{Yu} \mathrm{H}$, Cho J. Prevalence of internet gaming disorder among Korean adolescents and associations with non-psychotic psychological symptoms, and physical aggression. Am J Health Behav. 2016;40(6):705-16. https://doi.org/10.5993/ajhb.40.6.3 PMid:27779939

8. Wartberg L, Kriston L, Thomasius R. The prevalence and psychosocial correlates of internet gaming disorder: Analysis in a nationally representative sample of 12 -to 25 -year-olds.
Deut Ärzt Int. 2017;114(25):419. https://doi.org/10.3238/ arztebl.2017.0419

9. Siste K, Hanafi E, Sen LT, Wahjoepramono PO, Yudistiro R. Potential correlates of internet gaming disorder among indonesian medical students: Cross-sectional study. J Med Intern Res. 2021;23(4):e25468. https://doi.org/10.2196/ preprints. 29790

PMid:33871379

10. Cole H, Griffiths MD. Social interactions in massively multiplayer online role-playing gamers. Cyberpsychol Behav. 2007;10(4):575-83. https://doi.org/10.1089/cpb.2007.9988 PMid: 17711367

11. Brilliant TD, Nouchi R, Kawashima R. Does video gaming have impacts on the brain: Evidence from a systematic review. Brain Sci. 2019;9(10):251. https://doi.org/10.3390/brainsci9100251 PMid:31557907

12. Jap T, Tiatri S, Jaya ES, Suteja MS. The development of Indonesian online game addiction questionnaire. PLoS One. 2013;8(4):e61098. https://doi.org/10.1371/journal. pone.0061098

PMid:23560113

13. Kurniasanti KS, Assandi $P$, Ismail RI, Nasrun MW, Wiguna T. Internet addiction: A new addiction? Med J Indones. 2019;28(1):82-91. https://doi.org/10.13181/mji.v28i1.2752

14. Dong G, Lu Q, Zhou H, Zhao X. Precursor or sequela: Pathological disorders in people with Internet addiction disorder PLoS One. 2011;6(2):e14703. https://doi.org/10.1371/journal. pone.0014703 PMid:21358822

15. Andreassen CS, Pallesen S, Griffiths MD. The relationship between addictive use of social media, narcissism, and self-esteem: Findings from a large national survey. Addict Behav. 2017;64:287-93. https://doi.org/10.1016/j. addbeh.2016.03.006

16. Lim JA, Lee JY, Jung HY, Sohn BK, Choi SW, Kim YJ, et al. Changes of quality of life and cognitive function in individuals with Internet gaming disorder: A 6-month follow-up. Medicine. 2016;95(50):e5695. https://doi.org/10.1097/ md.0000000000005695

PMid:27977620

17. Paulus FW, Ohmann S, Von Gontard A, Popow C. Internet gaming disorder in children and adolescents: A systematic review. Dev Med Child Neurol. 2018;60(7):645-59. https://doi. org/10.1111/dmcn.13754

PMid:29633243

18. Long J, Liu T, Liu Y, Hao W, Maurage P, Billieux J. Prevalence and correlates of problematic online gaming: A systematic review of the evidence published in Chinese. Curr Addict Reports. 2018;5(3):359-71. https://doi.org/10.1007/s40429-018-0219-6

19. Stavropoulos V, Alexandraki K, Motti-Stefanidi F. Recognizing internet addiction: Prevalence and relationship to academic achievement in adolescents enrolled in urban and rural Greek high schools. J Adolesc. 2013;36(3):565-76. https://doi. org/10.1016/j.adolescence.2013.03.008 PMid:23608781

20. Shi J, Boak A, Mann R, Turner NE. Adolescent problem video gaming in urban and non-urban regions. Int $\mathrm{J}$ Mental Health Addict. 2019;17(4):817-27. https://doi.org/10.1007/ s11469-018-9872-1

21. Kurnianingsih N, Ratnawati R, Yudhantara DS, Prawiro RB, Permatasari $\mathrm{M}$, Rachma $\mathrm{H}$, et al. Association between time spent for internet gaming, grade point average and internet gaming disorder risk among medical students. Res J Life Sci. 2018;5(3):140-8. https://doi.org/10.21776/ub.rjls.2018.005.03.1

22. Jang JH, Chung SJ, Choi A, Lee JY, Kim B, Park M, et al. 
Association of general cognitive functions with gaming use in young adults: A comparison among excessive gamers, regular gamers and non-gamers. J Clin Med. 2021;10(11):2293. https:// doi.org/10.3390/jcm10112293

PMid:34070386

23. Jain M, Passi G. Assessment of a modified mini-mental Scale for cognitive functions in children. Indian Pediatr. 2005;42(9):907. PMid: 16208050

24. Arthy CC. Validitas Dan Reliabilitas Game Addiction Scale (GAS) Versi Bahasa Indonesia (Validity and Reliability of Game Addiction Scale-Indonesian Version). Medan, Indonesia: University of North Sumatra, Indonesia; 2019. https://doi. org/10.15562/jdmfs.v13i3.405

25. Lemmens JS, Valkenburg PM, Peter J. Development and validation of a game addiction scale for adolescents. Media Psychol. 2009;12(1):77-95. https://doi. org/10.1080/15213260802669458

26. Saputra HE, Handryastuti S, Mangunatmadja I, Widodo DP, Pardede SO. Ouvrier's modified mini mental state examination as a screening test for cognitive impairment in school-aged children with epilepsy. Paediatr Indones. 2020;60(3):137-41. https://doi.org/10.14238/pi60.3.2020.137-41

27. Moura R, Andrade PM, Fontes PL, Ferreira FO, Salvador LS, Carvalho MR, et al. Mini-mental state exam for children (MMC) in children with hemiplegic cerebral palsy. Dementia Neuropsychol. 2017;11:287-96 https://doi. org/10.1590/1980-57642016dn11-030011

28. Vidyanti AN, Hardhantyo M, Wiratama BS, Prodjohardjono A, $\mathrm{Hu}$ CJ. Obesity is less frequently associated with cognitive impairment in elderly individuals: A cross-sectional study in Yogyakarta, Indonesia. Nutrients. 2020;12(2):367. https://doi. org/10.3390/nu12020367

PMid:32019161

29. Brunborg GS, Mentzoni RA, Melkevik OR, Torsheim T, Samdal O Hetland J, et al. Gaming addiction, gaming engagement, and psychological health complaints among Norwegian adolescents. Med Psychol. 2013;16(1):115-28. https://doi.org/10.1080/15213 269.2012.756374

30. Donati MA, Chiesi F, Ammannato G, Primi C. Versatility and addiction in gaming: The number of video-game genres played is associated with pathological gaming in male adolescents. Cyberpsychol Behav Soc Netw. 2015;18(2):129-32. https://doi. org/10.1089/cyber.2014.0342

PMid:25684613

31. Zhou Z, Yuan G, Yao J. Cognitive biases toward Internet gamerelated pictures and executive deficits in individuals with an internet game addiction. PLoS One. 2012;7(11):e48961. https:// doi.org/10.1371/journal.pone.0048961

PMid:23155434

32. Zhou Z, Zhou H, Zhu H. Working memory, executive function and impulsivity in Internet-addictive disorders: A comparison with pathological gambling. Acta Neuropsychiatr. 2016;28(2):92- 100. https://doi.org/10.1017/neu.2015.54 PMid:26400106

33. Weinstein A, Livny A, Weizman A. New developments in brain research of internet and gaming disorder. Neurosci Biobehav Rev. 2017;75:314-30. https://doi.org/10.1016/j. neubiorev.2017.01.040 PMid:28193454

34. Wang Z, Wu L, Yuan K, Hu Y, Zheng H, Du X, et al. Cortical thickness and volume abnormalities in internet gaming disorder: Evidence from comparison of recreational internet game users. Eur J Neurosci. 2018;48(1):1654-66. https://doi.org/10.1111/ ejn.13987

\section{PMid:29883011}

35. Ouvrier R, Goldsmith R, Ouvrier S, Williams I. The value of the mini-mental state examination in childhood: A preliminary study. J Child Neurol. 1993;8(2):145-8. https://doi. org/10.1177/088307389300800206

PMid:8505476

36. Nys G, Van Zandvoort M, De Kort P, Jansen B, Kappelle L, De Haan E. Restrictions of the mini-mental state examination in acute stroke. Arch Clin Neuropsychol. 2005;20(5):623-9. https:// doi.org/10.1016/j.acn.2005.04.001

PMid:15939186

37. Lees R, Selvarajah J, Fenton C, Pendlebury ST, Langhorne P, Stott DJ, et al. Test accuracy of cognitive screening tests for diagnosis of dementia and multidomain cognitive impairment in stroke. Stroke. 2014;45(10):3008-18. https://doi.org/10.1161/ strokeaha.114.005842 PMid:25190446

38. Fu C, Jin X, Chen B, Xue F, Niu H, Guo R, et al. Comparison of the mini-mental state examination and Montreal cognitive assessment executive subtests in detecting post-stroke cognitive impairment. Geriatr Gerontol Int. 2017;17(12):2329- 35. https:// doi.org/10.1111/ggi.13069

PMid:28675607

39. Farchakh Y, Haddad C, Sacre H, Obeid S, Salameh P, Hallit S Video gaming addiction and its association with memory, attention and learning skills in Lebanese children. Child Adolesc Psychiatry Mental Health. 2020;14(1):1-11. https://doi. org/10.1186/s13034-020-00353-3

PMid:33308272

40. Park MH, Park EJ, Choi J, Chai S, Lee JH, Lee C, et al. Preliminary study of Internet addiction and cognitive function in adolescents based on IQ tests. Psychiatry Res. 2011;190(2- 3):275-81. https://doi.org/10.1016/j.psychres.2011.08.006 PMid:21899895

41. Wee CY, Zhao Z, Yap PT, Wu G, Shi F, Price T, et al. Disrupted brain functional network in internet addiction disorder: A restingstate functional magnetic resonance imaging study. PLoS One. 2014;9(9):e107306. https://doi.org/10.1371/journal. pone.0107306

42. Hutton JS, Dudley J, Horowitz-Kraus T, DeWitt T, Holland SK. Associations between screen-based media use and brain white matter integrity in preschool-aged children. JAMA Pediatr. 2020;174(1):e193869. https://doi.org/10.1001/ jamapediatrics.2019.3869 PMid:31682712

43. Bargeron AH, Hormes JM. Psychosocial correlates of internet gaming disorder: Psychopathology, life satisfaction, and impulsivity. Comput Hum Behav. 2017;68:388-94. https://doi. org/10.1016/j.chb.2016.11.029

44. Macur M, Pontes HM. Internet gaming disorder in adolescence: Investigating profiles and associated risk factors. BMC Public Health. 2021;21(1):1-9. https://doi.org/10.1186/s12889-021-11394-4

45. Lee D, Namkoong K, Lee J, Jung YC. Abnormal gray matter volume and impulsivity in young adults with Internet gaming disorder. Addict Biol. 2018;23(5):1160-7. https://doi.org/10.1111/ adb. 12552

\section{PMid:28884950}

46. Colzato LS, van den Wildenberg WP, Zmigrod S, HommelB.Action video gaming and cognitive control: Playing first person shooter games is associated with improvement in working memory but not action inhibition. Psychol Res. 2013;77(2):234-9. https:// doi.org/10.1007/s00426-012-0415-2

PMid:22270615 